\title{
BMJ Open Prescription contraception use: a cross-sectional population study of psychosocial determinants
}

\author{
Gerard J Molloy, ${ }^{1,2}$ Leigh-Ann Sweeney, ${ }^{1,2}$ Molly Byrne, ${ }^{1,2}$ Carmel M Hughes, ${ }^{3}$ \\ Roger Ingham, ${ }^{4}$ Karen Morgan, ${ }^{5,6}$ Andrew W Murphy ${ }^{7}$
}

To cite: Molloy GJ, Sweeney L-A, Byrne M, et al. Prescription contraception use: a cross-sectional population study of psychosocial determinants. BMJ Open 2015;5:e007794. doi:10.1136/bmjopen-2015007794

- Prepublication history for this paper is available online To view these files please visit the journal online (http://dx.doi.org/10.1136/ bmjopen-2015-007794).

Received 28 January 2015

Revised 8 May 2015

Accepted 12 May 2015

CrossMark

For numbered affiliations see end of article.

Correspondence to

Gerard J Molloy;

gerry.molloy@nuigalway.ie

\section{ABSTRACT}

Objective: Many forms of contraception are available on prescription only for example, the oral contraceptive pill (OCP) and long-acting reversible contraceptives (LARCs). In this analysis we aim to identify key determinants of prescription contraceptive use. Design: Cross-sectional population survey. Data on sociodemographic indices, concerns about the OCP and perceived barriers to access were collected.

Setting: Data set constructed from a representative population-based telephone survey of community dwelling adults in the Republic of Ireland (Rol)

Participants: 1515 women aged between 18 and 45 years

Main outcome measure: Self-reported user of the OCP or LARCs (intrauterine contraception, contraceptive injections or subdermal contraceptive implants) in the previous 12 months.

Results: For at least some of the previous year, $35 \%$ had used the OCP and $14 \%$ had used LARCs, while $3 \%$ had used two or more of these methods. OCP users were significantly younger, more likely to be unmarried and had higher income than non-users. Overall, $68 \%$ agreed with the statement 'that taking a break from long-term use of the contraceptive pill is a good idea' and $37 \%$ agreed with the statement that 'the OCP has dangerous side effects' and this was the strongest predictor variable of non-use of the OCP. Intrauterine contraception users were significantly older, more likely to be married and had lower income than non-users. Injections or subdermal contraceptive implant users were significantly younger, less likely to be married, had lower income and were less likely to agree that taking a break from long-term use of the pill is a good idea than non-users.

Conclusions: Prescription contraceptive use is sociodemographically patterned, with LARCs in particular being associated with lower incomes in the Rol. Concerns about the safety of the OCP remain prevalent and are important and modifiable determinants of contraceptive-related behaviour.

\section{INTRODUCTION}

Many of the most effective and widely used methods of contraception usually require a

\section{Strengths and limitations of this study}

- This is the first study to provide a detailed population level multivariable analysis of a range of psychosocial determinants of prescription contraceptive use, including concerns about the safety of the oral contraceptive pill, in a representative sample of over 1500 women in the Republic of Ireland.

- The study data were self-reported in a telephone interview and may be subject to recall and social desirability biases; however this is a widely used method to collect data on sexual health from large samples, and has established reliability and validity.

- The identification of both modifiable and nonmodifiable determinants of prescription contraceptive use can inform targeted interventions to improve sexual and reproductive health.

prescription from a physician. ${ }^{1}$ Data from the United Nations indicates that in more economically developed regions, the oral contraceptive pill (OCP), which is one such method, is second only to male condom use $(18.4 \%)$ with an estimated international prevalence rate of $17.7 \%$ in women who are in a stable relationship. ${ }^{1}$ OCP use has remained constant or has increased over the past 10 years in many countries, including Republic of Ireland (RoI) and the $\mathrm{UK}^{2}{ }^{3}$ The user-dependent nature of the OCP means that the failure rate of the OCP is substantially greater than long-acting reversible contraception (LARCs) methods for example, intrauterine contraception and subdermal contraceptive implants. ${ }^{4}$ However, it is important to note that these methods are not suitable for all women. ${ }^{5}$ There is also evidence that negative attitudes and misconceptions about specific types of LARC may be pervasive $^{67}$ including among healthcare providers; ${ }^{8}{ }^{9}$ therefore, use of these methods remains much lower than the OCP in many countries. $^{1}$ 
Previous studies have shown that certain types of prescription contraception tend to be more widely used by certain demographic groups. However, these studies are somewhat dated, of variable methodological quality and from a limited range of sociocultural contexts. ${ }^{10}$ Additionally, these studies have not examined the independence of sociodemographic predictors in accounting for prescription contraception use. Some of these predictors become more closely related over time. For example, age and marital status have become more strongly associated with each other due to the increasing age at which people marry and the rapidly changing patterns of relationship stability in some countries. ${ }^{11}{ }^{12}$ It is also possible that there may be age-dependent beliefs about contraception, for example, the OCP, which could determine its use. This may be due to the high profile reporting of health risks associated with earlier versions of the OCP to which older contraceptive users may have been exposed and the improved safety of more recent versions of the OCP. ${ }^{5}$ In the context of RoI, there is also evidence that older contraceptive users may not have received information on contraception as part of their formal sex education. ${ }^{2}$ Analyses examining how beliefs about the OCP vary by age are necessary in order to elucidate under what conditions a range of factors explain patterns of OCP use.

Beliefs about the safety of medical treatments are of particular interest as these variables are potentially modifiable determinants of uptake and adherence to prescription contraception. There is a significant body of research focusing on the 'Necessity-Concerns framework' of treatment adherence over the past 15 years. ${ }^{13} 14$ This approach emphasises the individual's judgement of personal need for medication or other forms of treatment (necessity beliefs) and concerns about the potential adverse consequences of taking it for example, side effects and long-term use. Although much of this literature focuses on chronic illness, more recent work has identified similar associations between these treatment beliefs and adherence to the OCP, particularly concerns about the OCP. ${ }^{15}$ This latter study was in a small sample of students $(\mathrm{N}=130)$ in the UK, therefore the external validity of these findings is limited. In the present study, we examine whether a range of sociodemographic variables, including concerns about the OCP and barriers to access can account for prescription contraception use in a representative sample of women between the ages of 18 and 45 in the general population in RoI. Specifically, we examine OCP use and two types of LARC use, namely intrauterine contraception and contraceptive injections or subdermal contraceptive implants. Although some studies have combined these into one LARC user category, ${ }^{16}$ it is likely that the characteristics of users vary for these methods given the previous trends to avoid intrauterine contraception in nulliparous women. ${ }^{17} 18$ Therefore, we assess intrauterine contraception use and contraceptive injections or subdermal contraceptive implants use separately in our analysis.
Although these represent three distinct prescription contraception methods, the latter two methods are combined into one category in this study measure, due to the low frequency of use of contraceptive injections and subdermal contraceptive implants.

\section{METHOD}

\section{Study design}

Data were drawn from women who participated in the Irish Contraception and Crisis Pregnancy Study 2010 (ICCP-2010). ${ }^{2}$ This was a nationally representative crosssectional survey of men and women between the ages of 18 and 45 who were living in $\operatorname{RoI}(\mathrm{N}=3002$; women $\mathrm{n}=1515$ ). The study was designed to describe attitudes, knowledge and behaviours relating to sexual health and, in particular, contraception and crisis pregnancy. Crisis pregnancy in this context was defined as "a pregnancy that represents a personal crisis or an emotional trauma in either of the following circumstances: (a) a pregnancy that began as a crisis, even if the crisis was subsequently resolved or (b) a pregnancy that develops into a crisis before the birth due to a change in circumstances." 2

\section{Setting and sample}

This population-based telephone survey was conducted in 2010. The random digit dialling of both landline and mobile phones and the quota sampling technique that was used to ensure a representative sample of the general population within this age band are described in detail in the main report and a separate publication. ${ }^{2}{ }^{19}$ The overall response rate to the survey was $69 \%$.

\section{Recruitment and consent}

A standardised introduction to the study was used to describe who was carrying out the survey, its confidential nature and how the telephone numbers had been randomly selected. Following confirmation that the respondent was over 18 years of age and verbal agreement to participate, the telephone interview began.

\section{Questionnaire survey}

The telephone-administered questionnaire collected information on the participant's sociodemographic data, living arrangements, children, sex education, knowledge and attitudes about contraception, contraceptive use over the past year, sources of contraception and contraceptive services, sexually transmitted infections, most recent sexual partnership, experience of pregnancy and knowledge of crisis pregnancy services, including abortion. The full questionnaire and data set are available on request from the Irish Social Science Data Archive. For the present study, we highlight 10 variables in our main analyses; these psychosocial variables were selected based on previous literature and variables that capture aspects of an individual's motivation, capability and opportunity to use prescription contraception, as 
defined by the behaviour change wheel approach for identifying factors for behaviour change interventions. ${ }^{20}$

\section{Sociodemographic data}

In addition to age in years, data were gathered on marital and relationship status (married, separated, divorced, widowed and never married), education (primary or incomplete secondary only, complete secondary and third level) and whether respondents were in receipt of general medical services (GMS). Such entitlement is based on an assessment of individual's income and is therefore a reliable indicator of socioeconomic status; individuals with GMS have lower incomes. In 2010, approximately $40 \%$ of the population in RoI had GMS eligibility. At the time of this survey patients with such eligibility receive all medications, including contraceptives, free of charge; non-GMS patients pay for all prescriptions up to a monthly limit of approximately $€ 90$.

\section{Prescription contraception use in the past year}

In order to assess prescription contraception use, respondents were asked 'Which of these methods of contraception or precautions to avoid pregnancy have you and any partner (s) used together in the last year?' The first contraceptive mentioned on this list was 'The contraceptive pill'. The fifth contraceptive method mentioned on the list was 'Coil, intrauterine device or intrauterine system (Mirena)'. The eleventh method mentioned was 'Injections (Depo Provera) or Implanted contraceptive capsules' (Implanon). If respondents used these in the past year, they were scored as 1 and if not, they were scored as 0 . It is important to note that this would not necessarily refer to continuous use of these methods. Participants were also asked which methods of contraception or precautions to avoid pregnancy had they ever heard of as part of this section.

\section{Concerns about the OCP}

Two items assessed concerns about the contraceptive pill. These were, 'The contraceptive pill has dangerous side-effects' and 'Taking a break from the long-term use of the contraceptive pill is a good idea'. These were scored on a five-point scale from 1 Strongly Agree to 5 Strongly Disagree. Higher scores related to lower concerns. There was a small to moderate positive correlation between these two items $(\mathrm{r}=0.15, \mathrm{p}<0.01)$, which indicates that they can be treated as distinct but related aspects of concerns about the OCP. A 'Don't know' response that was not part of the five-point scale was used by approximately $3 \%$ of the participants; therefore, the two concern variables were dichotomised into 'Agree' versus 'Other' to preserve cases in the analyses. Those scoring Strongly Agree and Agree were classified as 'Agree' and all other responses were classified as 'Other'.
Barriers to access

Various barriers to accessing contraception were assessed in ICCP-2010. These included the following items: Do not know where to get contraception/services, cannot access contraception/services in your locality, are embarrassed about accessing contraception/services, cannot afford contraception/services. The responses to these items were 'Yes' or 'No'. As less than $1 \%$ of the overall sample responded 'Yes' to the item 'Do not know where to get contraception/services,' this variable was not included in the analyses. Therefore, these four variables are binary variables where participants were classified as Yes or No. Participants were also asked 'How difficult do you find it to get contraception?' Responses were provided on a four-point scale from 1 very difficult to 4 not at all difficult.

\section{Data analyses}

Descriptive statistics were calculated for the main study variables in order to characterise the sample. Independent $\mathrm{t}$ tests and $\chi^{2}$ tests for independence were used to compare groups on continuous and categorical data respectively. Logistic regression analyses were used to test multivariable models. The final complete multivariable model allowed the statistical independence of the predictive variables to be established. Logistic regression provides ORs and 95\% CIs for each predictor of prescription contraception use, which calculates estimates of effect sizes for the study predictors. As there were 536 OCP users (35\%) and 152 intrauterine contraception users $(10 \%)$ in this sample $(n=1515)$, there were sufficient numbers of events per variable to use our multivariable logistic regression with 10 predictors. ${ }^{21}$ As there were only 67 women using injections or subdermal contraceptive implants $(4 \%)$ this analysis could provide less reliable estimates with 10 predictors. Moderation analyses were carried out using the moderation script for SPSS developed by Hayes and Matthes. ${ }^{22}$ Moderation analyses were used to assess whether there were agedependent associations between beliefs about the OCP and OCP use. This tested whether the strength of the association between beliefs about the OCP and OCP use varies for different age groups. All analyses were weighted to ensure that the results are representative of the population. Full details of the weighting parameters used are provided in the ICCP-2010 report. $^{2}$

\section{RESULTS}

\section{Sample}

An outline of the sample characteristics grouped by prescription contraception users and non-users of that method is provided in table 1. Forty-four women (3\%) had used two or more of the OCP, intrauterine contraception, contraceptive injections or subdermal contraceptive implants in the previous year, therefore the totals do not equal 1515 participants in table 1 . The three most widely used methods of contraception were 


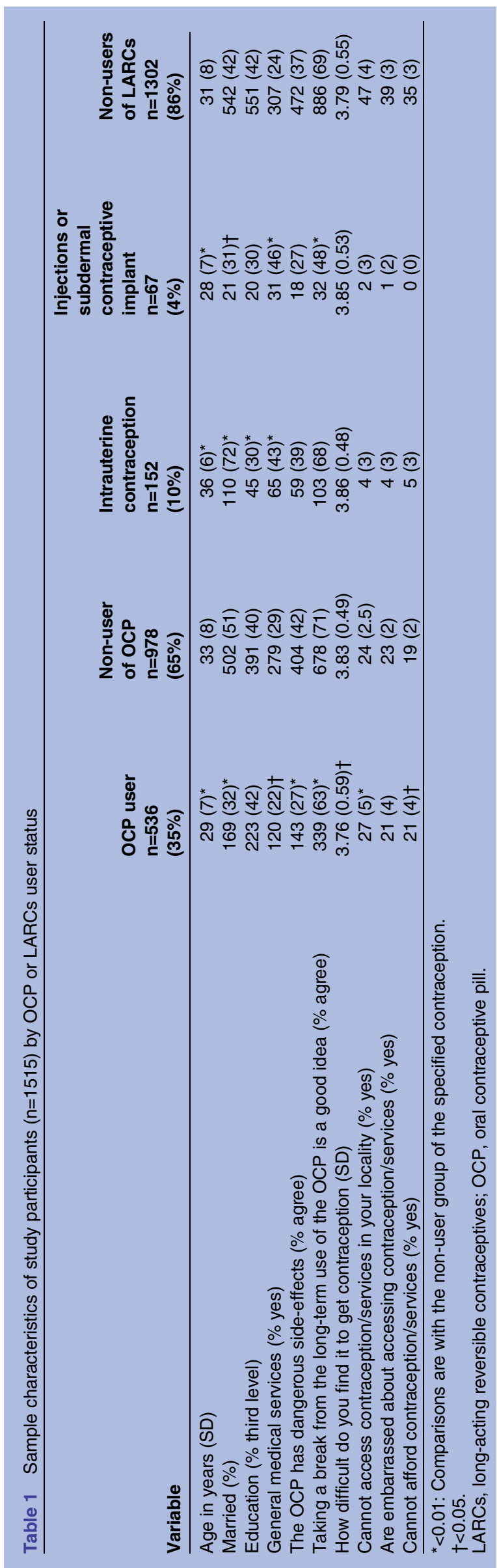

condoms $(39 \%)$, the OCP $(35 \%)$ and the intrauterine contraception $(10 \%)$. The 'non-users of LARCs' column in table 1 refers to participants who neither used intrauterine contraception use nor subdermal contraceptive implants as a method of contraception in the previous year. Full details of the study sample are provided elsewhere. ${ }^{2}$ Eighty-three per cent had heard of the OCP, $76 \%$ had heard of intrauterine devices/systems and $72 \%$ had heard of injections or subdermal contraceptive implants. Only $5 \%$ of women had not used any method of contraception in the previous year. OCP users, compared with non-OCP users, were significantly younger, were less likely to be married, less likely to be in receipt of GMS, less likely to believe that the pill has dangerous side effects, less likely to believe that taking a break from the long-term use of the contraceptive pill is a good idea, more likely to report difficulty in getting contraception, more likely to report that they could not access contraception/services in their locality and more likely to say they could not afford contraception/services. Intrauterine contraception users were significantly older, more likely to be married, less likely to have third level education and more likely to be in receipt of GMS. Injections or subdermal contraceptive implants users were more likely to be significantly younger, more likely to be unmarried, more likely to be in receipt of GMS and less likely to believe that taking a break from the long-term use of the contraceptive pill is a good idea. In the total sample $(\mathrm{n}=1515), 37 \%$ agreed with the statement that the OCP had dangerous side effects and $68 \%$ agreed that taking a break from long-term use of the contraceptive pill was a good idea. The proportion of participants in all groups who reported barriers to access was relatively low that is, $\leq 5 \%$.

In the multivariable analysis presented in table 2, all study variables were included regardless of univariate associations in order to assess the statistical independence of these determinants. In this table, ORs less than 1 are associated with non-use of the method; for example, being married and having general medical services were associated with non-use of the OCP as shown in table 2. The multivariable model shows that younger age, being unmarried, not being in receipt of GMS and not believing that the OCP has dangerous side effects emerged as significant independent predictors of OCP use. The strongest predictor was not agreeing with the statement that 'The contraceptive pill has dangerous side effects'. This overall pattern of findings did not change when the continuous measures of education and concerns about the OCP were included in place of the dichotomised variables. In table 2 intrauterine contraception use and subdermal contraceptive implants use are compared with non-use of these methods. Older age, being married and being in receipt of GMS were significant predictors of intrauterine contraception use, while younger age, being in receipt of GMS and not agreeing that taking a break from the long-term use of the contraceptive pill is a good idea were significant 
Table 2 Multivariable logistic regression predicting prescription contraception use ( $1=\mathrm{Yes}, 0=\mathrm{No})$ among study participants $\left(\mathrm{n}=1515^{\star}\right)$

\begin{tabular}{|c|c|c|c|c|c|c|}
\hline \multirow[b]{2}{*}{ Predictor variable } & \multicolumn{2}{|l|}{ OCP } & \multicolumn{2}{|c|}{$\begin{array}{l}\text { Intrauterine } \\
\text { contraception }\end{array}$} & \multicolumn{2}{|c|}{$\begin{array}{l}\text { Injections or } \\
\text { subdermal } \\
\text { contraceptive } \\
\text { implant }\end{array}$} \\
\hline & $\overline{\text { OR }}$ & $95 \% \mathrm{Cl}$ & $\overline{O R}$ & $95 \% \mathrm{Cl}$ & $\overline{O R}$ & $95 \% \mathrm{Cl}$ \\
\hline Age in years (continuous) & $0.92 \dagger$ & 0.91 to 0.94 & $1.10 \dagger$ & 1.06 to 1.13 & $0.92 \dagger$ & 0.88 to 0.97 \\
\hline Unmarried (reference) & 1.00 & & 1.00 & & 1.00 & \\
\hline Married & $0.67 \dagger$ & 0.51 to 0.89 & $2.48 \dagger$ & 1.62 to 3.80 & 1.09 & 0.56 to 2.13 \\
\hline Education at third level-no (reference) & 1.00 & & 1.00 & & 1.00 & \\
\hline Education at third level-yes & 0.83 & 0.65 to 1.07 & 0.74 & 0.49 to 1.12 & 0.74 & 0.41 to 1.32 \\
\hline General medical services-no (reference) & 1.00 & & 1.00 & & 1.00 & \\
\hline General medical services-yes & $0.62 \dagger$ & 0.46 to 0.83 & $2.63 \dagger$ & 1.76 to 3.91 & $2.31 \dagger$ & 1.33 to 3.99 \\
\hline The OCP has dangerous side effects-other (reference) & 1.00 & & 1.00 & & 1.00 & \\
\hline The OCP has dangerous side effects-agree & $0.52 \dagger$ & 0.43 to 0.68 & 1.19 & 0.81 to 1.76 & 0.84 & 0.47 to 1.49 \\
\hline $\begin{array}{l}\text { Taking a break from the long-term use of the OCP is a } \\
\text { good idea-other (Ref) }\end{array}$ & 1.00 & & 1.00 & & 1.00 & \\
\hline $\begin{array}{l}\text { Taking a break from the long-term use of the OCP is a } \\
\text { good idea-agree }\end{array}$ & 0.89 & 0.68 to 1.15 & 0.73 & 0.49 to 1.11 & $0.48 \dagger$ & 0.28 to 0.81 \\
\hline How difficult do you find it to get contraception (continuous) & 0.80 & 0.56 to 1.15 & 1.32 & 0.66 to 2.66 & 0.92 & 0.44 to 1.91 \\
\hline $\begin{array}{l}\text { Cannot access contraception/services in your locality-no } \\
\text { (reference) }\end{array}$ & 1.00 & & 1.00 & & 1.00 & \\
\hline Cannot access contraception/services in your locality-yes & 1.20 & 0.55 to 2.63 & 1.13 & 0.26 to 4.97 & 0.71 & 0.11 to 4.45 \\
\hline $\begin{array}{l}\text { Are embarrassed about accessing contraception/services } \\
- \text { no (reference) }\end{array}$ & 1.00 & & 1.00 & & 1.00 & \\
\hline $\begin{array}{l}\text { Are embarrassed about accessing contraception/services } \\
\text {-yes }\end{array}$ & 0.69 & 0.32 to 1.52 & 1.48 & 0.39 to 5.68 & 0.16 & 0.01 to 2.13 \\
\hline Cannot afford contraception/services—no (reference) & 1.00 & & 1.00 & & 1.00 & \\
\hline Cannot afford contraception/services--yes & 0.88 & 0.40 to 1.92 & 2.31 & 0.63 to 8.44 & 0.99 & 0.00 to 0.00 \\
\hline Nagelkerke $R^{2}$ for full model & & 0.17 & & 0.18 & & 0.11 \\
\hline
\end{tabular}

predictors of injections or subdermal contraceptive implants use. Being in receipt of GMS was the strongest predictor of both LARCs methods. The multivariate models accounted for a moderate amount of variability in prescription contraception use as indicated by the Nagelkerke $\mathrm{R}^{2}$ value.

Respondents who agreed that 'The contraceptive pill has dangerous side effects' were significantly older $(\mathrm{M}=32.26, \mathrm{SD}=7.83$ years vs $\mathrm{M}=31.42, \mathrm{SD}=7.41$ years, $\mathrm{t}=$ $-2.06, \mathrm{p}=0.04)$, as were respondents who agreed that 'Taking a break from the long-term use of the contraceptive pill is a good idea $(\mathrm{M}=32.61, \mathrm{SD}=7.44$ years vs $\mathrm{M}=29.87, \mathrm{SD}=7.53, \mathrm{t}=-6.60, \mathrm{p}<0.01)$. In moderation analyses, there was no significant interaction between age and believing that the OCP had dangerous side-effects in predicting OCP use. However, there was a significant interaction between age and believing that taking a break from the long-term use of the contraceptive pill was a good idea (interaction term $\beta=-0.05, \mathrm{p}<0.01$ ). These age-dependent associations are provided in table 3 below. This table compares the strength of this association, that is, $\beta$ values, at $1 \mathrm{SD}$ above and below the mean value of the moderator variable that is, age.
In older women, that is, those $1 \mathrm{SD}$ above the mean age of 31.85 years agreeing with this statement was strongly predictive of pill non-use, whereas this was not the case among younger women that is, those $1 \mathrm{SD}$ below the mean age. This decomposition of the interaction into these three groups is recommended by statistical texts describing this analytical method. ${ }^{22}$

\section{DISCUSSION}

The analysis provides a detailed description of the characteristics of prescription contraception users in

Table 3 Association between agreeing that 'taking a break from the oral contraceptive pill is a good idea' and OCP non-use across younger, average and older age groups

\begin{tabular}{lrllr}
\hline Age in years & \multicolumn{1}{l}{$\boldsymbol{\beta}$} & SE & 95\% Cl $\boldsymbol{\beta}$ & p Value \\
\hline $24.23(-1 \mathrm{SD})$ & 0.09 & 0.15 & $-0.20,0.39$ & 0.53 \\
31.85 (mean) & -0.26 & 0.12 & $-0.50,-0.02$ & 0.03 \\
39.46 (+ 1SD) & -0.61 & 0.19 & $-0.98,-0.24$ & $<0.01$ \\
\hline
\end{tabular}


RoI. Lower income, as indexed by having GMS, was the strongest predictor of both kinds of LARC use. These results highlight that concerns about the OCP are common and that these concerns are linked to prescription contraception use, with the strongest predictor of not using the OCP being the belief that 'the contraceptive pill has dangerous side-effects'. The analysis also shows that the association between concerns and OCP use varied according to age, with the association being particularly strong among older women. This might be partly explained by exposure to historical reporting of specific health risks associated with the OCP that have since been shown to be unsupported. ${ }^{5}$ It is also likely that the increased duration of exposure to the OCP that older users will have may also partly account for this. In the ICCP-2010 report ${ }^{2}$ there was evidence indicating that contraception was a topic in the sex education of $70 \%$ of those between the ages of 18 and 25 years of age in the survey, but only $34 \%$ of those between the ages of 36 and 45 years of age said that contraception was mentioned. This might also partly explain the greater concerns about OCP reported by older women, as it is likely that accurate information about contraception was harder to access.

The independent links between prescription contraception use and age, marital status and having GMS that is, having lower income, are consistent with observations seen in other countries. ${ }^{10}$ The prevalence and predictive power of the two variables assessing concerns about the OCP suggests that concerns may continue to have an important role in contraceptive choice, as has been observed in earlier studies in other contexts. ${ }^{23}$ The low numbers of respondents reporting barriers to access $(\leq 5 \%)$ and the weak predictive power of 'perceived difficulty' of finding contraception measure suggest that access to contraception is no longer reported as a major problem among adults in RoI and probably not an important determinant of OCP use. However, it is important to acknowledge that there may be barriers to access in those under $18 .^{24}$ The findings relating to sex education in ICCP- $2010^{2}$ do indicate that contraception is more likely to be part of the sex education of younger cohorts. However, it is not universally covered according to the data and there is a relatively recent history of avoiding the topic in sex education, ${ }^{2}$ which may create and reflect implicit social disapproval of contraception.

The predictive power of 'concerns about the OCP' and the potentially modifiable nature of these beliefs suggest that reproductive health promotion needs to place particular emphasis on shaping accurate beliefs about the OCP and indeed LARCs' methods to optimise individual contraceptive choices. In addition to this, it is clear that there are socioeconomic determinants of OCP use in that the current results show that OCP use was more common among those who did not have GMS that is, those with higher income, and LARCs use was more common among those who did have GMS that is, those with lower incomes. Therefore, although few people indicated that they could not afford contraceptive services $(<5 \%)$, it is likely that there are socioeconomic barriers to contraception use. Recent intervention studies, including natural experiments, suggest that removing financial and other access barriers can have a substantial impact on uptake of contraceptives, particularly LARCs. ${ }^{25} 26$

The OCP is currently a significantly less expensive option in the short term for those who do not have GMS costing less than €20 per month. Therefore, it is possible that LARCs methods, which may cost up to $€ 300$ initially, are not financially feasible for those with incomes just above the threshold that would entitle them to GMS. As a result, LARC use may predominate in those with lowest incomes who do qualify for GMS and those with higher incomes in RoI, where the initial higher cost is not a barrier. It is also worth noting that this socioeconomic difference seen within RoI reflects socioeconomic differences between other countries in respect of LARC use. For example, intrauterine contraception is more commonly used and often freely available in less economically developed parts of the world, for example, in Asia, there is a $27 \%$ prevalence among women using contraception, whereas it is a relatively expensive option in many more wealthier regions for example, $6 \%$ prevalence in North America. ${ }^{18}$ The socioeconomic distribution of LARCs use in RoI is likely to reflect the non-universal coverage of prescription contraceptive costs for both the recipients and providers of contraceptive services.

Contraception has been a controversial sociopolitical topic in the RoI. Prescribing and having contraception of any description was illegal in the RoI until $1980^{27}$ and emergency contraception was not available without prescription until $2011 .^{28}$ This can be largely explained by the particular religious ethos that historically pervaded healthcare and politics in RoI. ${ }^{29}$ This might also partly explain the greater concerns about OCP reported by older women in the present study. Given this cultural backdrop, policy measures such as providing free contraceptive services to all may be likely to receive resistance in RoI from religious lobby groups, even if evidence from health economic analysis in other contexts indicates that this investment may lead to health gain for the population. ${ }^{30}$

\section{Limitations and strengths}

There are a number of aspects of the methodology where alternative approaches would have been desirable. First, the data were entirely self-reported in the format of a telephone interview. This is subject to the usual problems of recall and social desirability biases in measurement. However, this is a widely used approach with established reliability and validity that may be superior to face-to-face interviews for sensitive topics. ${ }^{31}$ Second, the cross-sectional study design does not allow any causal inferences to be made from the data, as temporality in the relationships between variables cannot be 
established. Third, it would have been preferable to have psychometrically validated measures of concerns about the pill $^{15}$ and other related psychological constructs related to medication beliefs ${ }^{14}$ and LARCs rather than the single item measures used in this study that only addressed the OCP. Fourth, there are a number of additional measures that were not included that would have provided useful information on contraceptive choice; for example, whether the combined oral contraceptive or the progesterone only pill was used and/or whether the participant's reason for using contraception was for contraception only or for other medical reasons. Finally, this is a unique healthcare context where funding models for contraceptive services differ from many other healthcare systems.

Nevertheless, there are several strengths to the present study which help to mitigate these limitations, including the representative sample of the general population within the specified age band who provided anonymised data, the reporting of multivariable and moderation analyses to provide a more detailed and nuanced assessment of the relationship between a broad range of predictors and prescription contraceptive use, the separate analyses for two different classes of LARCs which are sometimes considered together, ${ }^{16}$ and the use of relatively recently collected data on this topic. This is particularly important due to the changing nature of contraceptive use over the past 1015 years in this ${ }^{2}$ and other international contexts. ${ }^{1}$

\section{CONCLUSION}

Prescription contraceptive use is sociodemographically patterned with LARCs methods in particular being associated with lower incomes in RoI. Despite the established safety of the OCP, concerns remain prevalent in RoI, which may reflect the sociocultural context surrounding contraception. These concerns are important and modifiable determinants of contraceptive-related behaviour that appear to have more resonance among older users of contraception. The evidence from this study suggests that further efforts are required to clarify the health risks associated with the OCP and LARCs. Future work will also need to establish who (eg, GP or nurse), where (eg, primary care or educational settings) and how (eg, during consultations or sex education classes), this can be optimally delivered.

\footnotetext{
Author affiliations

${ }^{1}$ School of Psychology, National University of Ireland, Galway, Republic of Ireland

${ }^{2}$ Whitaker Institute for Innovation and Societal Change, National University of Ireland, Galway, Republic of Ireland

${ }^{3}$ School of Pharmacy, Queen's University Belfast, Belfast, Northern Ireland, UK ${ }^{4}$ Centre for Sexual Health Research, University of Southampton,

Southampton, UK

${ }^{5}$ Department of Psychology, Royal College of Surgeons in Ireland, Dublin, Republic of Ireland

${ }^{6}$ Perdana University Royal College of Surgeons in Ireland School of Medicine, Malaysia

${ }^{7}$ Discipline of General Practice, School of Medicine, National University of Ireland, Galway, Republic of Ireland
}

Contributors GJM, KM, MB and AWM conceived the research. GJM carried out the research, data analysis and drafted the paper. All authors commented on and approved the final manuscript.

Funding This study was funded by a project grant awarded by the Health Service Executive Crisis Pregnancy Programme and administered by the Irish Research Council in December 2013 to Dr GJM (Principal Investigator), KM, $\mathrm{MB}$ and AWM (coinvestigators). $\mathrm{CMH}, \mathrm{RI}$ and Professor Richard Layte were members of the steering committee for this study. The original ICCP-2010 study was also funded by the Health Service Executive Crisis Pregnancy Programme.

Competing interests None declared.

Patient consent Obtained.

Ethics approval The original ICCP-2010 survey protocol received ethical approval from the Research Ethics Committee of the Royal College of Surgeons in Ireland (RCSI) and the programme of work that includes the present analysis received ethical approval from the NUI Galway Research Ethics Committee (Reference: 14/Jan/03).

Provenance and peer review Not commissioned; externally peer reviewed.

Data sharing statement There ICCP-2010 data set is available from the Irish Social Science Data Archive: http://www.ucd.ie/issda/ The survey questionnaire is available at: http://www.ucd.ie/t4cms/ICCP_2010_-_main_ questionnaire.pdf.

Open Access This is an Open Access article distributed in accordance with the Creative Commons Attribution Non Commercial (CC BY-NC 4.0) license, which permits others to distribute, remix, adapt, build upon this work noncommercially, and license their derivative works on different terms, provided the original work is properly cited and the use is non-commercial. See: http:// creativecommons.org/licenses/by-nc/4.0/

\section{REFERENCES}

1. United Nations. World contraceptive patterns. 2013. http://www.un. org/en/development/desa/population/publications/family/ contraceptive-wallchart-2013.shtml (accessed 16 Dec 2014).

2. McBride $\mathrm{O}$, Morgan $\mathrm{K}, \mathrm{McGee} \mathrm{H}$. Irish contraception and crisis pregnancy study 2010 (ICCP-2010): a survey of the general population. Dublin: Crisis Pregnancy Programme, 2012.

3. Lader D. Opinions survey report No. 41 contraception and sexual health, 2008/09. London: Office for National Statistics, 2009.

4. Trussell J. Contraceptive failure in the United States. Contraception 2011;83:397-404

5. Sitruk-Ware R, Nath A, Mishell DR Jr. Contraception technology: past, present and future. Contraception 2013;87:319-30.

6. Glasier A, Scorer J, Bigrigg A. Attitudes of women in Scotland to contraception: a qualitative study to explore the acceptability of longacting methods. J Fam Plann Reprod Health Care 2008;34:213-17.

7. Okpo E, Allerton L, Brechin S. 'But you can't reverse a hysterectomy!' Perceptions of long acting reversible contraception (LARC) among young women aged 16-24 years: a qualitative study. Public Health 2014;128:934-9.

8. Wellings $\mathrm{K}$, Zhihong Z, Krentel A, et al. Attitudes towards long-acting reversible methods of contraception in general practice in the UK. Contraception 2007;76:208-14.

9. Rubin SE, Davis K, McKee MD. New York city physicians' views of providing long-acting reversible contraception to adolescents. Ann Fam Med 2013;11:130-6.

10. Mosher WD, Jones J. Use of contraception in the United States: 1982-2008. Vital Health Stat 23 2010;(29):1-44.

11. Central Statistics Office. Marriages and Civil Partnerships 2011 Secondary Marriages and Civil Partnerships 2011. 2013. http://www. cso.ie/en/releasesandpublications/er/mcp/marriagesandcivil partnerships2011/\#.U9kT0vldX-8 (accessed 16 Dec 2014).

12. Office for National Statistics. Marriages in England and Wales (Provisional), 2012. Secondary Marriages in England and Wales (Provisional), 2012. 2014. http://www.ons.gov.uk/ons/rel/vsob1/ marriages-in-england-and-wales--provisional-/2012/index.html (accessed 16 Dec 2014).

13. Horne R, Chapman SC, Parham R, et al. Understanding patients adherence-related beliefs about medicines prescribed for long-term conditions: a meta-analytic review of the Necessity-Concerns Framework. PloS ONE 2013;8:e80633. 
14. Horne R, Weinman J, Hankins M. The beliefs about medicines questionnaire: the development and evaluation of a new method for assessing the cognitive representation of medication. Psychol Health 1999;14:1-24.

15. Molloy GJ, Graham H, McGuinness H. Adherence to the oral contraceptive pill: a cross-sectional survey of modifiable behavioural determinants. BMC Public Health 2012;12:838.

16. Kavanaugh ML, Jerman J, Hubacher D, et al. Characteristics of women in the United States who use long-acting reversible contraceptive methods. Obstet Gynecol. 2011;117: 1349-57.

17. Black K, Lotke $\mathrm{P}$, Buhling $\mathrm{KJ}$, et al. Intrauterine contraception for nulliparous women: translating research into action $\mathrm{g}$. A review of barriers and myths preventing the more widespread use of intrauterine contraception in nulliparous women. Eur J Contracept Reprod Health Care 2012;17:340-50.

18. Buhling KJ, Zite NB, Lotke $\mathrm{P}$, et al. Worldwide use of intrauterine contraception: a review. Contraception 2014;89:162-73.

19. McBride $\mathrm{O}$, Morgan $\mathrm{K}, \mathrm{McGee} \mathrm{H}$. Recruitment using mobile telephones in an Irish general population sexual health survey: challenges and practical solutions. BMC Med Res Methodol 2012;12:45

20. Michie S, van Stralen MM, West R. The behaviour change wheel: a new method for characterising and designing behaviour change interventions. Implement Sci 2011;6:42.

21. Peduzzi P, Concato J, Kemper E, et al. A simulation study of the number of events per variable in logistic regression analysis. $J$ Clin Epidemiol 1996;49:1373-9.
22. Hayes AF, Matthes J. Computational procedures for probing interactions in OLS and logistic regression: SPSS and SAS implementations. Behav Res Methods 2009;41:924-36.

23. Bongaarts J, Bruce J. The causes of unmet need for contraception and the social content of services. Stud Fam Plann 1995;26:57-75.

24. Bankole A, Malarcher S. Removing barriers to adolescents' access to contraceptive information and services. Stud Fam Plann 2010;41:117-24.

25. Secura GM, Allsworth JE, Madden T, et al. The Contraceptive CHOICE Project: reducing barriers to long-acting reversible contraception. Am J Obstet Gynecol 2010;203:115.e1-7.

26. Postlethwaite D, Trussell J, Zoolakis A, et al. A comparison of contraceptive procurement pre- and post-benefit change. Contraception 2007;76:360-5.

27. S.I. No. 248/1980-Health (Family Planning) Regulations. 1980. http://www.irishstatutebook.ie/1980/en/si/0248.html (accessed 16 Dec 2014).

28. RTÉ. IPU welcomes morning-after pill decision. Secondary IPU welcomes morning-after pill decision. 2011. http://www.rte.ie/news/ 2011/0216/297748-pill/ (accessed 16 Dec 2014).

29. Girvin B. Church, state, and society in Rol since 1960. Éire-Rol 2008;43:74-98.

30. Secura GM, Madden T, McNicholas C, et al. Provision of no-cost, long-acting contraception and teenage pregnancy. N Engl J Med 2014;371:1316-23.

31. True K, Bajos N, Bohet A, et al. Timing of contraceptive initiation and association with future sexual and reproductive outcomes. Hum Reprod 2014;29:1651-8. 